UDC 616.517-053.2-056.5-031.74

DOI: 10.15587/2519-4798.2020.221120

\title{
BIOCHEMICAL INDICATORS AND COURSE OF DERMATOSIS IN CHILDREN WITH PSORIASIS DEPENDING ON THE BODY MASS INDEX
}

\section{E. Murzina}

The aim. To study the effect of increased body weight in children with psoriasis on the indicators of the biochemical profile and the severity of the pathological process.

Materials and methods. The indicators of the biochemical profile were studied in 108 children, namely: the level of total protein, total bilirubin, cholesterol, liver enzymes (ALT, AST, GGT), triglycerides and low density lipoproteins, creatinine, urea, uric acid (UA), depending on the mass index body (BMI). The research materials were statistically processed using parametric analysis methods using the STATISTICA 13.3 software (developed by StatSoft. Inc).

Results. Lipid profile indices both in the group of children with normal BMI and in the group of children with increased BMI are within the reference values. Statistically significant differences were found between the average GGT level in the group of children with increased BMI compared with the indicators in the group of children with normal BMI and indicators in the children of the control group. Also, in children with increased BMI, the average UA level is statistically significant higher than in children of the control group and has direct moderate and significant correlations with indices of the severity of the pathological process. In children with increased BMI, psoriasis severity indices correlate with BMI: PGA $(r=0.51, p<0,01) B S A(r=0.48, p<0,01), P A S I$ at the beginning of treatment $(r=0.41, p<0,05)$ and PASI at the end of treatment $(r=0.67, p<0.001)$ and percentage of excess body weight: BSA $(r=0.34, p<0,05)$, PASI at the end of treatment $(r=0.67, p<0.001)$. In children with normal BMI, such correlations were not found

Key words. Psoriasis, children, psoriasis severity indices PASI, BSA and PGA, biochemical profile indicators, GGT, uric acid, body mass index

Copyright (C) 2020, E. Murzina.

This is an open access article under the CC BY license (http://creativecommons.org/licenses/by/4.0).

\section{Introduction}

Psoriasis is a potential multisystem disease with extradermal manifestations in many patients. Adult patients with psoriasis have many comorbidities that can affect the patient's general condition and reduce their quality of life, such as arthritis, cardiovascular disease, dyslipidemia, obesity, metabolic syndrome, and depression. It is believed that children with psoriasis may have the same comorbidity. Numerous scientific papers indicate that body weight increase leads to an increased risk of psoriasis, and weight loss has a positive effect on the course of the disease $[1,2]$. Because adipose tissue is metabolically active, it secretes pro-inflammatory cytokines, which further alter the metabolism of interleukins (IL) 1, IL-6, TNF- $\alpha$ and the anti-inflammatory cytokine, adiponectin. In obesity, the number of these proinflammatory cytokines increases, while the expression of adiponectin decreases [3, 4]. Similar to adults, studies have found that children with psoriasis have a higher prevalence of obesity than children without psoriasis, and some studies have shown a nearly two-fold prevalence (8.4\% vs. $4.9 \%$ [5] and 7, $1 \%$ vs. $3.6 \%$ ) [6].

An important role in the development of psoriasis is assigned to the study of metabolic disorders [7]. A systematic review conducted in 2019 showed that psoriasis in children is not associated with concomitant metabolic and cardiovascular diseases, with the exception of overweight and obesity [8]. Paller A. S. et al. believe that children with psoriasis and obesity are more prone to dyslipidemia in the blood than children with psoriasis and normal weight [9]. In a study by Goldminz A. M. et al 20 children with psoriasis aged 9 to 17 years with patients of the appropriate age and sex in whom acne, nevi and warts were observed, it was found that $30 \%$ of patients with childhood psoriasis met the criteria of metabolic syndrome compared with $5 \%$ of patients in the control group [10]. Other studies confirm that all children with psoriasis should be screened for cardiovascular and metabolic comorbidities, given the predisposition to such conditions [9, 11, 12].

The basic principles of management and treatment of psoriasis in children, developed jointly by the American Academy of Dermatology and the National Union of Psoriasis, offer universal lipid screening at the age of 9 to 11 years and at the age of 17 to 21 years. Patients at increased risk of dyslipidemia should be checked more frequently. Screening includes total cholesterol, highdensity lipoprotein cholesterol, LDL cholesterol, and triglyceride levels [13].

According to the results of our study, published earlier [14], we found that biochemical parameters in children with psoriasis, despite compliance with age reference values, indicate the presence of uric acid metabolism and signs of liver cell membrane damage, as evidenced by elevated levels uric acid (UA) and gammaglutamyltransferase (GGT) compared with children in the 
control group. UA and GGT levels increase with increasing severity of the pathological process, lead to prolonged exacerbation of psoriasis and resistance to prescribed therapy. To establish the effect of overweight in children with psoriasis on the biochemical profile and the course of the pathological process, the study was continued.

The aim of the research. To study the effect of overweight in children with psoriasis on the indicators of the biochemical profile and severity of the pathological process.

\section{Materials and methods}

The study group consisted of 108 children with psoriasis aged 4 to 17 years with a mean age of $12.11 \pm 0.44$ years, who were treated inpatient at the Kyiv City Clinical Dermatological and Venereological Hospital 2019-2020.

The calculation of the body mass index according to WHO recommendations [15] showed that 35 (28.70\%) children were overweight, so they found an elevated body mass index (BMI). The percentage of excess body weight from normal ranged from $3.05 \%$ to $39.78 \%$. Children depending on BMI were divided into 2 groups: group 1 - children with normal BMI - 77 children, group 2 - children with high BMI - 31 children. The average BMI in group $1-18.38 \pm 0.29 \mathrm{~kg} / \mathrm{m}^{2}$, in group $2-$ $25.04 \pm 0.64 \mathrm{~kg} / \mathrm{m}^{2}$.

In children, blood tests were performed for the following indicators: total protein, total bilirubin, cholesterol, liver enzymes (alanine aminotransferase (ALT), aspartate aminotransferase (AST), gamma-glutamyltransferase (GGT)), triglycerides and low-density lipoprotein, creatinine, urea, uric acid (UA). Biochemical studies were performed on a semi-automatic biochemical analyzer Biochem SA on the basis of the clinical laboratory of the Kyiv City Clinical Dermatological and Venereological Hospital.

The study of the biochemical profile is part of the complex examination of children in inpatient treatment, to which all patients or their parents gave informed con- sent at hospitalization. Also, the Ethics Commission of NMAPE named after P.L. Shupyk (Minutes No. 4 of 03.02.2020) approved and authorized this clinical trial, which complies with current legislation of Ukraine, modern ethical standards and principles of scientific clinical trials.

The severity of the course was determined by the indices of severity of the pathological process: the prevalence and severity of psoriasis (Psoriasis Area and Severity Index - PASI), skin surface area (Body Surface Area - BSA) and global assessment of psoriasis by a physician (Physician Global Assessment - PGA), which reflects pathological process, namely, erythema, peeling and infiltration [12].

The control group consisted of 18 children who did not have chronic skin diseases.

The study materials were statistically processed using parametric analysis methods using the program STATISTICA 13.3 (developer - StatSoft.Inc). When comparing the mean values of the populations, the Student's t-test was calculated, with the level of statistical significance $p<0.05$. Correlation analysis was performed by the Pearson method. The values of the correlation coefficient (r) were interpreted according to the Chaddock scale.

\section{Research results}

When determining the clinical and epidemiological characteristics of groups of children with psoriasis depending on BMI (Table 1) statistically significant differences between the indicators of the severity of psoriasis PGA in children with high BMI and in children with normal BMI were found. And there is a statistical tendency to the predominance of PASI before treatment in the group of children with elevated BMI over a similar indicator in the group of children with normal BMI. That is, the manifestations of psoriasis in children with elevated BMI were more intense than in children with normal BMI. The groups of children did not differ in other indicators $(\mathrm{p}>0.05)$.

Table 1

Clinical and epidemiological characteristics of groups of children with psoriasis depending on BMI

\begin{tabular}{|c|c|c|}
\hline \multirow[t]{2}{*}{ Indexes, unit of measurement } & \multicolumn{2}{|c|}{ Groups of children with psoriasis by BMI $((\mathrm{N}=108)$} \\
\hline & $\begin{array}{l}\text { BMI is within normal limits } \\
\text { Group } 1(\mathrm{~N}=77)\end{array}$ & $\begin{array}{l}\text { BMI is above normal } \\
\text { Group } 2(\mathrm{~N}=31)\end{array}$ \\
\hline Average age, years & $12.23 \pm 0.40$ & $13.07 \pm 0.48$ \\
\hline Onset of the disease, year & $9.46 \pm 0.46$ & $9.31 \pm 0.82$ \\
\hline Duration of the disease, years & $2.69 \pm 0.37$ & $3.97 \pm 0.81$ \\
\hline Duration of exacerbation, weeks & $11.55 \pm 1.88$ & $15.88 \pm 2.87$ \\
\hline PASI before the treatment & $11.34 \pm 1.36$ & $16.91 \pm 3.28$ \\
\hline PASI at the end of the treatment & $1.71 \pm 0.47$ & $2.08 \pm 0.66$ \\
\hline PGA & $2.53 \pm 0.11 *$ & $2.96 \pm 0.15 *$ \\
\hline BSA & $26.45 \pm 2.57$ & $29.24 \pm 4.084$ \\
\hline
\end{tabular}

Note: *-differences statistically significant at the level of $p \leq 0.05$ between groups

The study of lipid profile in children with psoriasis showed that in the group of children with normal BMI and in the group of children with elevated BMI, the levels of indicators are within the reference values. If we compare the biochemical profile between the group of children with psoriasis with normal BMI and the group of children with elevated BMI and the indicators of the control group, we have significant differences. Statistically significant differences were found between the average level of GGT $(22.14 \pm 1.72 \mathrm{U} / 1)$ in the group of children with elevated BMI compared with indicator in the group of children with normal BMI $(15.04 \pm 0.82 \mathrm{U} / \mathrm{l})$ 
and indicator in children of the control group $(12.90 \pm 1.01 \mathrm{U} / \mathrm{l})$. Bilirubin levels in children with psoriasis with both elevated BMI $(9.83 \pm 0.28 \mu \mathrm{mol} / \mathrm{l})$ and normal BMI $(9.63 \pm 0.33 \mu \mathrm{mol} / \mathrm{l})$ can be compared among themselves and are likely to be higher than indicator in children in the control group $(8.86 \pm 0.09 \mu \mathrm{mol} / \mathrm{l})$. Also, in children with elevated BMI, the average level of UA $(292.17 \pm 9.21 \mu \mathrm{mol} / \mathrm{l})$ is statistically significantly higher than in the control group of children $(256.8 \pm 9.39 \mu \mathrm{mol} / \mathrm{l})$ and has a statistical tendency to predominate over the average indicator in the group of children with normal BMI $(261.44 \pm 11.11 \mu \mathrm{mol} / \mathrm{l})$.

ALT activity in the group of children with elevated BMI $(18.32 \pm 2.95 \mathrm{U} / 1)$, although higher than in the control group (15.54 $\pm 1.12 \mathrm{U} / 1)$, but no significant differences were found (Table 2).

Biochemical parameters in children with psoriasis depending on BMI

Table 2

\begin{tabular}{|c|c|c|c|c|}
\hline \multirow[b]{2}{*}{$\begin{array}{l}\text { Indexes, unit of measure- } \\
\text { ment }\end{array}$} & \multirow[b]{2}{*}{ Reference values } & \multirow[b]{2}{*}{$\begin{array}{l}\text { Control group } \\
\qquad(\mathrm{N}=18)\end{array}$} & \multicolumn{2}{|c|}{ Groups of children with psoriasis by BMI } \\
\hline & & & $\begin{array}{c}\text { Group 1 } \\
(\mathrm{N}=77)\end{array}$ & $\begin{array}{c}\text { Group } 2 \\
(\mathrm{~N}=31)\end{array}$ \\
\hline Total protein, $\mathrm{g} / \mathrm{l}$ & $65-85$ & $73.33 \pm 1.10$ & $73.67 \pm 1.27$ & $71.76 \pm 1.43$ \\
\hline Urea, mmol/l & $1.8-6.4$ & $5.4 \pm 0.68$ & $4.46 \pm 0.22$ & $4.08 \pm 0.29$ \\
\hline Creatinine, $\mu \mathrm{mol} / 1$ & $44-88$ & $59.8 \pm 1.2$ & $61.43 \pm 1.02$ & $59.54 \pm 2.16$ \\
\hline Cholesterol, $\mathrm{mmol} / \mathrm{l}$ & $<5.2$ & $4.11 \pm 0.33$ & $4.48 \pm 0.13$ & $4.15 \pm 0.18$ \\
\hline Triglycerides, mmol/l & $0.5-1.8$ & $1.02 \pm 0.12$ & $0.93 \pm 0.06$ & $0.94 \pm 0.11$ \\
\hline LDL, $\mathrm{mmol} / \mathrm{l}$ & $28-53 \%$ of all lipids & $1.78 \pm 0.21$ & $1.98 \pm 0.15$ & $1.64 \pm 0.12$ \\
\hline Bilirubin, $\mu \mathrm{mol} / \mathrm{l}$ & $3.4-17.1$ & $8.86 \pm 0.09$ & $9.63 \pm 0.33$ & $9.83 \pm 0.28$ \\
\hline $\begin{array}{l}\text { The level of statistical sig- } \\
\text { nificance between groups } \\
\text { on the level of bilirubin }\end{array}$ & \multicolumn{4}{|c|}{$\mathrm{p}_{\mathrm{c} .1} \leq 0.05 ; \mathrm{p}_{\mathrm{c} .2} \leq 0.05$} \\
\hline ALT, U/l & $\begin{array}{l}\text { up to } 12 \text { years }-36 \text {; } \\
\text { girls } 12-17 \text { years old: }<25 \text {; } \\
\text { boys } 12-17 \text { years: <29; }\end{array}$ & $15.54 \pm 1.12$ & $16.01 \pm 0.77$ & $18.32 \pm 2.95$ \\
\hline AST, U/l & $\begin{array}{l}\text { up to } 15 \text { years }-5-42 \text {; } \\
\text { boys under } 17 \text { years: } 7-50 \text {; } \\
\text { girls under } 17 \text { years: } 5-44 \text {; }\end{array}$ & $28.46 \pm 2.55$ & $24.18 \pm 1.39$ & $21.71 \pm 1.61$ \\
\hline GGT, U/l & $\begin{array}{l}6-12 \text { years: up to } 17 \\
\text { boys } 12-17 \text { years: }<45 \text {; } \\
\text { girls } 12-17 \text { years: }<33\end{array}$ & $12.90 \pm 1.01$ & $15.04 \pm 0.82$ & $22.14 \pm 1.72$ \\
\hline $\begin{array}{l}\text { The level of statistical signif- } \\
\text { icance between groups ac- } \\
\text { cording to the level of GGT }\end{array}$ & \multicolumn{4}{|c|}{$\mathrm{p}_{\mathrm{c} .2} \leq 0.05 ; \mathrm{p}_{1.2} \leq 0.05$} \\
\hline Uric acid, $\mu \mathrm{mol} / \mathrm{l}$ & $\begin{array}{c}\text { children under } 14 \text { years: } \\
120-320 \\
14-17 \text { years: }<405\end{array}$ & $256.8 \pm 9.39$ & $261.44 \pm 11.11$ & $292.17 \pm 9.21$ \\
\hline $\begin{array}{l}\text { The level of statistical sig- } \\
\text { nificance between groups on } \\
\text { the level of uric acid }\end{array}$ & \multicolumn{4}{|c|}{$\mathrm{p}_{\mathrm{c} .2} \leq 0.05$} \\
\hline
\end{tabular}

In patients with psoriasis, the study of genetic factors in the development of psoriasis has identified hereditary biochemical defects. Thus, the genetic determination of metabolic disorders was established: more lipids and much less carbohydrate metabolism, which made it possible to consider this dermatosis as epidermal lipoidosis with changes in the lipid composition of psoriatic areas of the skin [16]. In our study, the lipid profile in children with psoriasis with both normal BMI and elevated BMI, was not only within the reference values, but was compared with those of children in the control group. Most of the changes were related to uric acid metabolism disorders and signs of liver cell membrane damage, as evidenced by increased GGT and bilirubin levels.

The results of the study by Li Yin et al. showed that patients with moderate to severe psoriasis have a high incidence of liver damage, manifested by abnormal levels of globulins, ALT, GGT, which can be compared with similar indicators in patients with erythrodermic and generalized pustular psoriasis [17]. All these deviations can increase the duration of hospitalization and treatment costs. The results of our previous studies have established the effect of GGT and UA levels in the serum of children with psoriasis on the severity of the pathological process and the degree of its resolution [14].

The correlation analysis of the dependence of biochemical parameters of children with psoriasis on BMI showed the presence of a direct significant correlation between BMI and UA level $(\mathrm{r}=0.55 ; \mathrm{p}<0.001)$ and $\mathrm{a}$ direct high correlation between the percentage of overweight and UA level $(r=0.66 ; \mathrm{p}<0.001)$. The level of GGT correlates with BMI $(\mathrm{r}=0.60 ; \mathrm{p}<0.001)$, and the level of triglycerides - with the percentage of excess normal body weight $(r=0.39 ; \mathrm{p}<0.001)$.

According to the results of the correlation analysis separately for groups of children with normal BMI (group 1) and BMI higher than normal (group 2), it was found that in children with psoriasis in group 1 GGT level correlates with BMI - direct moderate relationship $(r=0.36 ; p<0.01)$, which in turn correlates with the severity index of psoriasis PGA $(r=0.34 ; \mathrm{p}<0.01)$. 
In children of group 2, the correlation is strengthened and there are links with other indicators of blood biochemistry. There are direct significant correlations between BMI, the percentage of excess BMI and the level of UA ( $r=0.65 ; \mathrm{p}<0.001$ and $\mathrm{r}=0.65 ; \mathrm{p}<0.001)$; and triglyceride levels $(\mathrm{r}=0.50 ; \mathrm{p}<0.01$ and $\mathrm{r}=0.39, \mathrm{p}<0.05)$. UA levels in children of group 2 have direct correlations with all indices of severity of psoriasis: with PGA $(\mathrm{r}=0.41 ; \mathrm{p}<0.05)$; with BSA $(\mathrm{r}=0.44 ; \mathrm{p}<0.01)$, with PASI at the beginning of treatment $(\mathrm{r}=0.53 ; \mathrm{p}<0.01)$ and at the end of treatment $(\mathrm{r}=0.69 ; \mathrm{p}<0.001)$. Direct significant correlations were also found between GGT levels and severity indices: with PGA $(r=0.52 ; \mathrm{p}<0.01)$; with BSA $(\mathrm{r}=0.53 ; \mathrm{p}<0.01)$, with PASI at the beginning of treatment $(\mathrm{r}=0.60 ; \mathrm{p}<0.001)$.

That is, the absence of obvious changes in biochemical parameters in overweight children with psoriasis, only the beginning of disorders of the hepatobiliary system, which are already programmed and further increase in BMI and the percentage of excess weight will lead to obvious pathological changes.

Most psoriasis researchers find a relationship between body weight and the severity of psoriasis: mild to moderate psoriasis is more likely to be overweight, and severe psoriasis is more likely to be obese. L Becker et al. consider the link between obesity and psoriasis bidirectional. Thus, the development of obesity and an increase in the incidence of psoriasis and its severity is observed in 7-10 years - at the age when weight gain usually begins. More than $90 \%$ of patients with psoriasis who are overweight and/or obese have experienced the development of psoriasis approximately 2 years after the onset of weight gain [18].

The results of correlation analysis generally revealed a direct moderate correlation between BMI and PGA index $(r=0.44 ; p<0.001)$; PASI at the beginning of treatment $(\mathrm{r}=0.34 ; \mathrm{p}<0.001)$ and PASI at the end of treatment $(r=0.50 ; p<0.001)$. A more detailed correlation analysis by groups of children with psoriasis depending on BMI showed which groups formed these connections. It was found that at normal BMI the correlation between BMI and PGA is directly moderate $(\mathrm{r}=0.33$; $\mathrm{p}<0.01)$. There are no other connections. In the group of children with elevated BMI the correlations between BMI with psoriasis severity indices are direct moderate and significant: PGA ( $\mathrm{r}=0.52 ; \mathrm{p}<0.01)$, PASI at the beginning of treatment $(r=0.41 ; p<0.05)$, PASI at the end of treatment $(\mathrm{r}=0.67 ; \mathrm{p}<0.001)$ and BSA $(\mathrm{r}=0.48 ; \mathrm{p}<0.01)$. The percentage of excess body weight correlates with the PASI at the end of treatment $(\mathrm{r}=0.67 ; \mathrm{p}<0.001)$ and the BSA $(\mathrm{r}=0.34 ; \mathrm{p}<0.05)$

\section{Discussion of research results}

Thus, in children with psoriasis, despite the fact that the levels of biochemical parameters are within normal limits, some indicators, such as GGT and UA are elevated compared to the control group. Although GGT is the least specific of the liver enzymes, but the most sensitive, its serum concentrations not only increase earlier, but also persist longer. In children with psoriasis with elevated BMI - this may be the first signs of violation of the membranes of liver cells and changes in the functional state of the gallbladder and bile ducts. It is also believed that the activity of the enzyme GGT is associated with cardiometabolic conditions such as insulin resistance; development of hypertension; subclinical myocardial damage; formation of atheromatous plaques; the risk of diabetes, metabolic syndrome and its inherent oxidative stress; increasing the density of arteries. Such GGT levels in children with psoriasis with elevated BMI may be predictors of cardiovascular risk and early development of atherosclerosis [19].

Disorders of nitrogen metabolism, which is manifested by hyperuricemia, as a result of hyperproduction of immune complexes as a result of accelerated metabolism of purines in actively proliferating skin cells, have been discussed in the last century. But even today, the results of the correlation between serum uric acid levels and psoriasis remain contradictory. In some studies, up to 50 percent of patients had elevated uric acid levels. Hyperuricemia was also more common in patients with a common pathological process [20].

And if the levels of UA are in line with the Recommendation of the European League Against Rheumatism (EULAR) for the diagnosis and treatment of gout (2006, 2016), when hyperuricemia is considered a serum uric acid level above $360 \mu \mathrm{mol} / 1$ (6 $\mathrm{mg} / \mathrm{dl})$ [21], in our study in the group of children with normal BMI in $6.49 \%$ of children there is an elevated level of UA, and in the group of children with elevated BMI - the number of children with elevated UA is almost 3 times higher and equal to $16.13 \%$. That is, in children with overweight psoriasis uricemia is more common, which depends on the percentage of excess weight $(r=0.65, \mathrm{p}<0.001)$, and correlates with the intensity of the pathological process and the area of skin lesions.

Study limitations. In our study, we found elevated bilirubin levels in children with psoriasis compared with controls. However, we did not perform biochemical analysis to determine the levels of direct and indirect bilirubin to determine why children with psoriasis showed the same results, because this result was unexpected. In the future it is necessary to pay attention to the study of bilirubin fractions.

Prospects for further research. The study of biochemical indicators in children with psoriasis is one of the tasks of scientific work on the identification and management of the most significant risk factors for psoriasis in children and the formation of individualized treatment tactics with dynamic monitoring.

\section{Conclusions}

1. Indicators of lipid profile in children with psoriasis both in the group of children with normal BMI and in the group of children with elevated BMI are within the reference values, but the average levels of GGT and UA in the group of children with elevated BMI were statistically significantly higher than in the control group of children, and also the average level of GGT in the group of children with elevated BMI was statistically significantly higher than in the group of children with normal BMI.

2. In children with psoriasis, correlations were found between BMI and UA level $(r=0.55 ; \mathrm{p}<0.001)$, between BMI and GGT level $(r=0.60 ; p<0.001)$, which in the group of children with elevated BMI is stronger $(\mathrm{r}=0.65 ; \mathrm{p}<0.001)$, and UA and GGT levels in children 
with elevated BMI have moderate and significant correlations with psoriasis severity indices.

3. The study showed that in children with psoriasis with high BMI the course of psoriasis is characterized by more intense manifestations and a larger area of skin lesions by the pathological process, and direct correlations between BMI and psoriasis severity indices: PGA $(r=0.52 ; p<0.01)$, PASI at the beginning of treatment $(r=0.41 ; p<0.05)$, PASI at the end of treatment $(r=0.67$; $\mathrm{p}<0.001)$, BSA $(\mathrm{r}=0.48 ; \mathrm{p}<0.01)$.

4. It was found that in children with psoriasis with elevated BMI, the percentage of excess body weight correlates with the PASI index at the end of treatment $(\mathrm{r}=0.67 ; \mathrm{p}<0.001)$ and the BSA index $(\mathrm{r}=0.34 ; \mathrm{p}<0.05)$.

Thus, overweight in children with psoriasis is a factor that aggravates the course of psoriasis: it increases the area of the lesion and the intensity of skin manifestations, and worsens the prognosis of treatment. Overweight in children with psoriasis increases the relationship between the levels of uric acid metabolism and the severity of the disease, and increases the damage to the membranes of liver cells.

\section{Conflict of interests}

The author declares there is no conflict of interests.

\section{References}

1. Akcali, C., Buyukcelik, B., Kirtak, N., İnaloz, S. (2014). Clinical and laboratory parameters associated with metabolic syndrome in Turkish patients with psoriasis. Journal of International Medical Research, 42 (2), 386-394. doi: http://doi.org/10.1177/0300060513502891

2. Farshchian, M., Ansar, A., Sobhan, M. R. (2013). Psoriasis and risk factors of metabolic syndrome: A case-control study. Dermatology \& Cosmetic, 4 (1), 10-18.

3. Jensen, P., Thyssen, J. P., Zachariae, C., Hansen, P. R., Linneberg, A., Skov, L. (2012). Cardiovascular risk factors in subjects with psoriasis: a cross-sectional general population study. International Journal of Dermatology, 52 (6), 681-683. doi: http://doi.org/10.1111/j.1365-4632.2011.05408.x

4. Solomon, G. (2014). The role of weight loss in the treatment of psoriasis: evidence that psoriasis is a systemic inflammatory disorder linked to metabolic syndrome. British Journal of Dermatology, 170 (3), 492-493. doi: http://doi.org/10.1111/bjd.12877

5. Zhu, K. J., He, S. M., Zhang, C., Yang, S., Zhang, X. J. (2011). Relationship of the body mass index and childhood psoriasis in a Chinese Han population: A hospital-based study. The Journal of Dermatology, 39 (2), 181-183. doi: http://doi.org/10.1111/ j.1346-8138.2011.01281.x

6. Augustin, M., Radtke, M. A., Glaeske, G., Reich, K., Christophers, E., Schaefer, I., Jacobi, A. (2015). Epidemiology and Comorbidity in Children with Psoriasis and Atopic Eczema. Dermatology, 231 (1), 35-40. doi: http://doi.org/10.1159/000381913

7. Kim, C. R., Lee, J.-H. (2013). An Observational Study on the Obesity and Metabolic Status of Psoriasis Patients. Annals of Dermatology, 25 (4), 440-444. doi: http://doi.org/10.5021/ad.2013.25.4.440

8. Badaoui, A., Tounian, P., Mahé, E. (2019). Psoriasis and metabolic and cardiovascular comorbidities in children: A systematic review. Archives de Pédiatrie, 26 (2), 86-94. doi: http://doi.org/10.1016/j.arcped.2018.12.005

9. Paller, A. S., Mercy, K., Kwasny, M. J., Choon, S. E., Cordoro, K. M., Girolomoni, G. et. al. (2013). Association of Pediatric Psoriasis Severity With Excess and Central Adiposity. JAMA Dermatology, 149 (2), $166-176 . \quad$ doi: http://doi.org/10.1001/jamadermatol.2013.1078

10. Goldminz, A. M., Buzney, C. D., Kim, N., Au, S.-C., Levine, D. E., Wang, A. C. et. al. (2013). Prevalence of the Metabolic Syndrome in Children with Psoriatic Disease. Pediatric Dermatology, 30 (6), 700-705. doi: http://doi.org/10.1111/pde.12218

11. Jensen, P., Zachariae, C., Iversen, L., Hansen, P., Skov, L. (2014). Cardiovascular Risk Factors in Children and Adolescents with Psoriasis: A Case-control Study. Acta Dermato Venereologica, 94 (1), 76-78. doi: http://doi.org/10.2340/00015555-1607

12. Menter, A., Cordoro, K. M., Davis, D. M. R., Kroshinsky, D., Paller, A. S., Armstrong, A. W. et. al. (2020). Joint American Academy of Dermatology-National Psoriasis Foundation guidelines of care for the management and treatment of psoriasis in pediatric patients. Journal of the American Academy of Dermatology, 82 (1), 161-201. doi: http://doi.org/10.1016/j.jaad.2019.08.049

13. Osier, E., Wang, A. S., Tollefson, M. M., Cordoro, K. M., Daniels, S. R., Eichenfield, A. et. al. (2017). Pediatric Psoriasis Comorbidity Screening Guidelines. JAMA Dermatology, 153 (7), 698-704. doi: http://doi.org/10.1001/jamadermatol.2017.0499

14. Murzina, E. O. (2020). Dependence of indicators of the biochemical profile of children with psoriasis on the severity of the pathological process. Ukrainian Medical Journal, 5 (139), 1-5. doi: http://doi.org/10.32471/umj.1680-3051.139.192013

15. Obesity and overweight. Fact Sheet (2020). World Health Organization. Available at: https://www.who.int/newsroom/fact-sheets/detail/obesity-and-overweight

16. Pietrzak, A. (2010). Lipid Disturbances in Psoriasis: An Update. BAD, 535-612.

17. Yin, L., Hu, Y. Y., Guo, J., Tu, J., Yin, Z. Q. (2017). Liver dysfunction of psoriatic patients: low serum total protein and albumin increase hospital stays. Biomedical Research, 28 (13), 5-8.

18. Becker, L., Tom, W. L., Eshagh, K., Benjamin, L. T., Paller, A. S. (2014). Excess Adiposity Preceding Pediatric Psoriasis. JAMA Dermatology, 150 (5), 573-574. doi: http://doi.org/10.1001/jamadermatol.2014.324

19. Aksu, F., Caliskan, M., Yilmaz, Y. (2016). Gamma-glutamyltransferase and Markers of Subclinical Atherosclerosis in Patients with Psoriasis Kenan Demircioglu. Arteriosclerosis, Thrombosis, and Vascular Biology, 36, A441

20. Li, X., Miao, X., Wang, H., Wang, Y., Li, F., Yang, Q. et. al. (2016). Association of Serum Uric Acid Levels in Psoriasis. A Systematic Review and Meta-Analysis. Medicine, 95 (19), e3676. doi: http://doi.org/10.1097/md.0000000000003676

21. Obmen mochevoi kisloty i patogenez narushenii. Kompendium - lekarstvennye preparaty Podagra: vzgliad v buduschee. Available at: https://compendium.com.ua/tutorials/podagra/obmen-mochevoj-kisloty-i-patogenez-narushenij/

Elvina Murzina, $\mathrm{PhD}$, Associate Professor, Department of Dermatovenereology, Shupyk National Medical Academy of Postgraduate Education, Dorohozhytska str., 9, Kyiv, Ukraine, 04112

E-mail: elvina2003@ukr.net 